\title{
The Theory of Thinking and the Capacity to Mentalize: A Comparison of Fonagy's and Bion's Models
}

\author{
Carla Mantilla Lagos \\ Pontificia Universidad Católica del Perú
}

\begin{abstract}
This paper presents a comparison of two psychoanalytic models of how human beings learn to use their mental capacities to know meaningfully about the world. The first, Fonagy's model of mentalization, is concerned with the development of a self capable of reflecting upon its own and others' mental states, based on feelings, thoughts, intentions, and desires. The other, Bion's model of thinking, is about the way thoughts are dealt with by babies, facilitating the construction of a thinking apparatus within a framework of primitive ways of communication between mother and baby. The theories are compared along three axes: (a) an axis of the theoretical and philosophical backgrounds of the models; (b) an axis of the kind of evidence that supports them; and (c) the third axis of the technical implications of the ideas of each model. It is concluded that, although the models belong to different theoretical and epistemological traditions and are supported by different sorts of evidence, they may be located along the same developmental line using an intersubjective framework that maintains tension between the intersubjective and the intrapsychic domains of the mind.
\end{abstract}

Keywords: theory of mind, intersubjectivity, psychoanalysis, thinking, mentalization, Bion, Fonagy

Este artículo muestra la comparación entre dos modelos psicoanalíticos que dan cuenta de cómo los seres humanos alcanzan la posibilidad de usar sus capacidades mentales para conocer y comprender el mundo de un modo significativo. De un lado, el modelo de la mentalización de Fonagy se preocupa por el desarrollo de un sí mismo (self) capaz de reflexionar sobre los estados mentales propios y los de los demás, en términos de pensamientos, sentimientos y deseos. De otro lado, el modelo del pensamiento de Bion, se refiere al modo por el cual el bebé lidia con los pensamientos, y posibilita la construcción de un aparato para pensarlos y acceder a un entendimiento emocional de los mismos, dentro de un marco de comunicación primaria con la madre. Ambos modelos son comparados a través de tres ejes: (a) los antecedentes filosóficos y teóricos, (b) el tipo de evidencia, y (c) las implicaciones para la técnica psicoanalítica. Aunque ambos modelos pertenecen a diferentes tradiciones teóricas y epistemológicas, se concluye que las capacidades para pensar y mentalizar podrían ser ubicadas al interior de una misma línea de desarrollo. Para ello, es necesario utilizar un marco de referencia intersubjetivista, que sostenga la tensión entre los dominios intersubjetivos e intrapsíquicos de la mente. Palabras clave: teoría de la mente, intersubjetividad, psicoanálisis, pensamiento, mentalización, Bion, Fonagy

Correspondence concerning this article should be sent to Carla Mantilla Lagos, Calle Roma 148, 401 Lima 18, Perú. E-mail: cmantil@pucp.edu.pe 


\section{The Capacity to Mentalize}

In two pivotal papers called "Playing with Reality," Fonagy and Target (1996a, 1996b) offered a detailed description of the line of development about the acquisition of a capacity by which a child can reflect upon his own and on others' mental states in terms of intentions, beliefs, and desires, and can access a world ruled by psychologically meaningful interactions. This reflective self enables the individual to enter the representational world: We are subjects of our reflection and, at the same time, the ones who carry out the reflective and observational activity. This reflective self, capable of constructing representations about its own and other's actions, is distinguished from a pre-reflective self, which is the "[...] immediate - that is, unmediatedexperiencer of life [...]" (Fonagy, Steele, Steele, Moran, \& Higgit, 1991, p. 201), incapable of taking an observing and knowing stance with respect to itself. The reflective, or mentalizing, self develops from the exchanges with another mind in an intersubjective framework. In this process, the infant "[...] finds an image of himself in his mother's mind, as an individual with thoughts and feelings" (Fonagy, \& Target, 1996a, p. 229).

According to Fonagy and Target (1996b), the capacity to mentalize develops mainly from the integration of two modes of experiencing psychic reality, between the second and fifth year of life. The authors call these modes the psychic equivalence and the pretend mode.

In the psychic equivalence mode, the child experiences ideas as replicas of external reality. Ideas are not recognized as such, as there are no proper representations of oneself and others. The internal world is expected to function under the rules of physical causality and to correspond to external reality (Fonagy, 1991; Fonagy \& Target, 1996a).

This way of experiencing psychic reality alternates with the pretend mode. In this mode, when the child plays, he knows that ideas are just ideas because the context deliberately allows this, but he fails to relate this internal state to external reality. Internal reality is enriched with all this pretence and fantasy, which brings about a capacity to treat ideas as mental entities, but it does not occur in connection with external reality. In the pretend mode, ideas cannot threaten because of their disconnection with reality, it is impossible to grasp internal and external reality at the same time. The child oscillates between both modes, and it is through the process of their integration that the capacity to mentalize is achieved (Fonagy \& Target, 1996a, 1996b).

The authors note that this happens between the fourth and fifth year of life and is achieved with the help of parents, siblings, and peers whose minds are used by the child as containers of his own intentions, feelings, and beliefs, mainly in the context of play. The continual incorporation and presence of mental states into the dialogue and exchanges between the child and his playmates will provide the child with a framework so he can see his fantasies and ideas represented in the other's mind. In time, the child will introject not only the image of his mental processes in the other's mind, but also the representation of the process of making meaningful representations, that is, the capacity to mentalize.

Mentalization, according to Fonagy and Target (1996b), offers the child a number of advantages: the opportunity to find meaning in people's actions, a clear demarcation between inner and external reality, the capacity to manipulate mental representations defensively, a good level of intersubjective contact with others, and so on. Mentalization places the child more in touch with his own and other's feelings, beliefs, and desires; this reinforces attunement with other people.

Insofar as this capacity develops in an interpersonal framework, the presence of a unresponsive caregiver, incapable of thinking about her child in terms of mental states, would contribute drastically to a poor integration of the two modes of experiencing psychic reality that normally leads to mentalization. It has been shown that secure attachment facilitates the acquisition of the reflective function. The child feels safe, and a sensitive mother, who is capable of imagining her child's feelings, meets his needs. Therefore, the parent's capacity to mentalize will predict the child's attachment security and his own mentalizing development (Fonagy \& Target, 1997).

When a child has been mistreated and traumatized, in order to get rid of facing his parent's thoughts of him as malevolent and their intention of harming him, the child defends himself by inhibiting the development of mentalizing capacities. The child stops thinking about others in terms of intentions, beliefs, and desires, as they involve the danger of becoming real. Also, when physical violence is the means of communication between child and adult, the body will become the scenario for dealing with ideas, feelings, and thoughts. The child's incapacity to keep ideas in mind or to give meaning to actions will make him prone to action, increasing impulsiveness and violence toward his own body and other selves. The failure to find another's mind in which the child may see his own represented will lead to continuous attempts to find alternative ways of containment with increasing use of projection, less separation, and more dependence (Fonagy \& Target, 1995, 1997, 1998).

In brief, the capacity to reflect upon one's own self and on other selves in terms of beliefs, feelings, and desires is achieved through safe, meaningful, and emotional exchanges between child and mother, fostered by the relationships with siblings, peers, and mainly the father, and facilitated in the scenario of play.

\section{The Theory of Thinking}

The theory of thinking, published by Bion in 1962, is a theoretical contribution of great importance and many repercussions in psychoanalytic theory and practice. For Bion, thinking is a capacity that develops in order to deal with thoughts (Bion, 1967a).

Thoughts pre-exist in a primitive way, and their development causes the emergence of an thinking apparatus 
(Bleandonu, 1994). Thinking is achieved when the baby meets two requirements: the development of thoughts and an apparatus to cope with them (Bion, 1967a). But what is thinking, in Bion's terms? It is impossible to attribute complex forms of thinking, as we know them, to a very small baby. O'Shaughnessy (1988) notes that Bion refers to an early form of thinking, which is the predecessor and basis of later forms. Thinking in this context is the process by which the baby gets to know psychic qualities; it is an emotional experience driven by the need to know and understand his own psychic reality and that of other selves. The purpose of this experience is to make sense of incomprehensible feelings that the baby experiences in early life and that are different from physical stimuli, which are processed through physical channels: the body. Likewise, the baby needs a channel to process mental contents, just as the stomach digests food. The model proposed by Bion holds that, early on in life, there is a psychosomatic channel between mother and baby. This channel performs, for instance, the task of processing both the milk the child receives from its mother and the love that accompanies it.

According to Bion (1967a), thought develops at different levels. The most primitive thought is a pre-conception, that is, an inborn expectation that something matches something else, like mouth and nipple. When an expectation is met, a conception appears. Therefore, a conception comes with a relative state of satisfaction. Bion reserves the term thought to refer to the encounter of a pre-conception with an absence. Here, the baby is faced with a state of frustration, the frustration of a breast being absent. In the baby's mind, the absence of the breast is felt as the presence of a bad object, but if the baby is able to tolerate this state of frustration and need, he will recognize the absence of the object, and this "non-thing" will become a thought. With the repetition of these processes, new conceptions and thoughts are developed and, with them, an apparatus for thinking appears. These processes characterize what Bion refers to as the nonpsychotic apart of personality, concerned with a linking activity. It should be noted also that, for Bion, frustration tolerance is an innate factor (Grinberg, Sor, \& Tabak de Bianchedi, 1993).

If the baby is unable to tolerate frustration, his aim will be to get rid of it by evasion. Instead of a thought, a bad object remains in the baby's mind and he will try to expel it by an excessive use of projective identification. In normal circumstances, this mechanism is used by the baby to communicate his troubled feelings to the mother. By making the mother feel what he cannot tolerate in his mind, the mother, if well adjusted, will respond to her child by turning these intolerable feelings into more tolerable ones. If the mother is not capable of tolerating her child's projections, the infant will continue to communicate them to his mother with increased force. This will make the baby feel that his projections are stripped of their meaning, leading to the introjection of what Bion (1967a) called a "nameless dread"
(Bleandonu, 1994). The relation between the failure to build a mental apparatus and the psychotic part of personality will be explained in depth in the following pages.

Up to this point, I have mainly described the vicissitudes of thoughts and the different apparatus that result from dealing with them. I will offer a brief account of the concept of the alpha function and, then, I will link this concept to the model of container-contained that Bion (1962) created to better understand the development of the thinking apparatus.

For Bion (1962), the existence of an alpha function that transforms sensory impressions into material for dream thoughts must be assumed. With this function, it becomes possible to conceive of being awake and going to sleep, being conscious or unconscious. These sensory impressions related to emotional experience and turned into material for dream thoughts are called alpha elements (visual, auditory, or olfactory images). They will merge and form a screen called the contact barrier (Grinberg et al., 1993), which separates the unconscious from the conscious, the internal world from the external world. When the alpha function is not operating, sensory impressions remain undigested and become beta elements. These elements remain agglomerated and cannot be used for dream thoughts. Therefore, the failure of the alpha function to produce alpha elements will lead to a psychotic state in which the person is unable to dream, and the demarcation between the conscious and the unconscious is unclear. In normal conditions, the alpha function develops when communication and internalization processes, via projective identification between mother and baby, are adequate (Bion, 1967a). If the mother is there to help her baby to tolerate frustration and to make sense of his incomprehensible feelings, his sensory and emotional impressions are turned into alpha elements. Therefore, the alpha function, performed by the mother in a state Bion (1962) called "reverie," is, over time, introjected by the child and used as part of his capacity to make sense of things. Thereby, the acquisition of a thinking apparatus develops within a dynamic and intersubjective relationship between the mother, as an object capable of containing, and a baby who projects feelings that have to be contained.

The mechanism represented by the relationship between the paranoid-schizoid and depressive positions (Ps $\leftrightarrow \mathrm{D})$ functions with the container-contained model. By Ps $\leftrightarrow \mathrm{D}$, Bion (1962) means a movement from disintegration to integration states that brings about a selected fact. The selected fact is something that organizes chaos, introducing coherence into what is dispersed and disorganized. Again, we observe the idea of something unorganized and confused that becomes understandable and tolerable, something that is "digested" and invested with sense.

To summarize: The thinking apparatus develops in an intersubjective framework where the mother contains and transforms what her baby cannot into organized and coherent contents that are pleasant for the baby and crucial for the acquisition of his future capacity to produce and to deal with thoughts. 


\section{Theoretical Background and Philosophical Influences}

The two models belong to different theoretical traditions: There is nothing new in that. Fonagy's model belongs to a contemporary Freudian perspective in which Anna Freud's concept of developmental line is crucial. Mental processes are understood as products of development and not as elements which are given. Behind this is probably the Freudian idea of an Ego that develops from an Id in response to adaptation to reality. Totally different are most Kleinian ideas about the ego, which, according to Klein, is present from birth in a primitive way. Bion comes from a Kleinian tradition, but he was interested in constructing a metapsychology complementary to Klein's meta-psychology. He was known as a "meta-theoretician."

Bion, like Fonagy, sees the capacity to think as a process that needs to develop within an inter-subjective relationship. Fonagy is rigorous in describing like a developmental psychologist the developmental sequence of the capacity to mentalize. He also places his theory in an intersubjective framework. However, in Fonagy's model, there are figures other than the mother that are clearly taken into account. There are constant references to the familiar environment, the role of the father, siblings, and peers. Bion is mainly concerned with the mother- (or primary caregiver) and-baby dyad, probably because the development of the thinking apparatus occurs very early, whereas the reflective self described by Fonagy develops mainly between the second and fifth year of life.

Another point of comparison is the weight each author gives to innate and environmental factors. Even though Fonagy mentions cases in which an impaired capacity to mentalize is due to constitutional conditions such as chronic illness or disability, he mainly attributes the failure to develop the reflective function to the lack of a caregiver who is able to reflect upon the child's mental states in terms of beliefs, desires, and feelings (Fonagy \& Target, 1998). There is causality in the idea of a trans-generational transmission of the reflection function, the importance of the actual parental figures is pivotal. For Bion (1967a, b), the innate proportion of the death instinct and its manifestation in envy and lack of frustration tolerance is crucial. These elements will influence and obscure normal development, making the child attack everything that links him to the awareness of reality. This will impair his capacity to develop thoughts and a thinking apparatus, even if there is a seemingly adequate mother.

Both models are concerned with a function (alpha and reflective function) that develops not within the baby's self, but from the meaningful interactions between the baby and another self, or selves, in the case of the reflective function. The incorporation of this object (the function) by either introjection or internalization is for both models the decisive goal that is achieved from this inter-subjective relationship.

The capacity to think and to mentalize can be seen as part of the same line of development, and the alpha function seems to be the seed for the reflective function. Therefore,
Fonagy's model could be seen as complementary to and extensive of Bion's model and others' ' (Fonagy \& Target, 1996b). For the authors of the series "Playing with reality," the path followed by a "Bionian" baby in the formation of early concepts will resemble the process of experiencing psychic reality in their model.

Bion's interest in meta-psychology is revealed in his ideas about the foundations of psychoanalysis (Lansky, 1981), his theory of functions, and the notations shown in the grid (Bion, 1988 ) are an example of that. Wisdom (1981) explains Bion's aim of having a strong metapsychology to understand thinking. Fonagy shares a metapsychological interest insofar as the capacity to mentalize is a meta-psychological process: The child has to learn to think about thinking (Fonagy \& Target 1996b).

There is another similarity in the dialectic nature of the models. Although Fonagy's model is explained in terms of a line of development, this does not imply total linearity. For example, there are fluctuations and movements between both ways of experiencing psychic reality in the pre-reflective self: psychic equivalence and pretend modes. Also, the intersubjective framework in which the synthesis of these modes brings about mentalization corresponds to a dialectical model: the internalization of a reflective function (Fonagy \& Target, 1996a). In Bion's model, the dialectic quality of the Ps $\leftrightarrow D$ is more obvious and well known (Steiner, 1992), as Klein herself described both positions as being in constant movement and fluctuation within the personality. Bion's model also resembles Hegel's idea of synthesis as an integrative product from the dialectical dynamic between a thesis and an antithesis. However, Klein sees a movement from the depressive to the paranoid schizoid position as a defense against depressive anxiety. For Bion, in normal projective identification, there should be a healthy movement between the positions. For example, in creative thinking, previous ideas must be dismantled before creating new ones. For this purpose, the previous container has to be dissolved and then restored with the new theories and ideas. In this dissolution, a state of fragmentation is reached and with this, a movement to the paranoid schizoid position is made. When the new ideas are implemented and the container is reformed, the depressive position re-emerges (Hinshelwood, 1991). In other words, a psychic change implies flexibility between the positions. Coming back to Hegel, it can be observed that, in the case of Fonagy's theory, a synthesis of the movements between the psychic equivalent and the pretend modes of experiencing psychic reality is represented by the reflective self. However, the dialectical nature (related to the positions in one case and the ways of experiencing psychic reality in the other) seems to be stronger in Bion's model than in Fonagy's, where, once the capacity to mentalize is reached, a regression to a previous way of experiencing psychic reality could be seen as symptomatic or defensive.

When examining a theory, it is interesting to study the philosophical influences that have been used as an epistemological basis. The philosophical ideas used as 
epistemological basis in Fonagy's theory belong to the tradition of the philosophy of mind. The author always relies on Davidsonian ideas about a mind created in relation to other minds (Fonagy \& Moran, 1991)

The work of Marcia Cavell (1993), who bridged psychoanalysis and philosophy of mind, supporting the idea that psychoanalysis could be seen as an extension of commonsense psychology, is essential here. Psychoanalysis, concerned with irrationality, fills the gaps that commonsense psychology left by considering rational processes as the only ones that can be understood in terms of beliefs and desires. The idea of a psychoanalytic encounter in which interpretation is possible because beliefs and desires are shared by people is crucial in Cavell's thought (Snelling, 2001). These ideas lend psychoanalysis an epistemological basis and this is exactly what Fonagy uses to sustain his findings. Cavell says that a child becomes a "subject" when he becomes able to communicate with others, when he can interpret others' behavior in terms of mental states, and become comprehensible to others in the same terms (Cavell).

According to Lansky (1981), Bion is a Kantian looking at Kleinian concepts. The influence of Kant is revealed in his constant interest in epistemology. The Kantian idea that things in the material world and in the mental apparatus share the nature of being unknowable is crucial for Bion's thinking. These things become knowable only when individuals apprehend from them the qualities that can be perceived by their senses and organized by their categories, creating a synthesis. Therefore, it is impossible to "know" a thing or a human being entirely because the only way truly to know either is by being that specific thing or that specific human being. In Bion's terms, there is a basic unknowability of anything that performs the alpha function. However, everything that undergoes thinking is transformed and knowable (alpha elements). On the other hand, beta elements, as things-in-themselves, remain unmetabolized and impossible to use because they have not been transformed into something knowable. Only when they are expelled via projective identification or transformed into hallucinations can they become shared as emotional or sensory experience, for example, by the analyst in session (Lansky).

With regard to the philosophical backgrounds, there seem to be striking differences between the models. For one thing, the mind is shared and public. Human beings are interpretable by other human beings insofar as they share the same mental states: They all desire and believe, and beliefs and desires are behind actions. In Bion's model, it seems impossible to really "know" something, even though there is a strong impulse to get to know someone else, called the $K$-link. There are still remains of an internalistic way of understanding mental processes, although the mechanism of projective identification, as the mother and baby's channel to communicate primitive contents, would be considered a step beyond a private conceptualization of the mind. It seems that Bion's model is midway between a pure internalistic model of the mind and a contemporary intersubjective and relational one.
However, in order to reach scientific status, a theoretical model should rely not only on a sound epistemological basis, but should be based on strong evidence.

\section{Evidence}

For the sake of clarity, when presenting the evidence found for each model, I will divide it into two groups: clinical and empirical. The clinical evidence is concerned with psychopathological manifestations that lead to or illustrate theoretical propositions in both models, whereas empirical evidence refers to research and experiments that support the findings of each theory.

Bion's model of thinking derives mainly from his work with schizophrenics (Grinberg et al., 1993). In one of his early works, he described how there are psychotic and nonpsychotic parts in everyone's personality. These parts become separated with one of them predominating over the other; finally they become unbridgeable (Bion, 1967). The aim of the psychotic part of the personality is to attack everything that enables the individual to be aware of reality. Thus, the individual will direct his attacks against anything that performs the function of linking. The part of psychic apparatus that performs this task is, precisely, consciousness; therefore, the psychotic patient will direct his attacks against his own apparatus for perceiving reality. Insofar as thinking enables the individual to get to know psychic and external reality, the psychotic person will attack his own capacity to develop a thinking apparatus (Bion, 1967a,b). Lacking an apparatus to deal with or "digest" sensory impressions and thoughts, the individual will develop an apparatus to get rid of unmetabolized elements. Instead of developing alpha elements, the individual will accumulate undigested facts, or beta elements. This apparatus will attempt to eject these beta elements by excessive use of projective identification. Once expelled, these elements will engulf objects of the reality that will acquire the characteristics of the part of the ego expelled (with superego parts), forming what Bion called bizarre objects (Bion, 1967a). For this individual, such objects will try to return in a retaliatory and persecutory way and will pervade his existence. As these bizarre objects contain the part of the ego related to the awareness of sensory impressions, the object will be felt as looking at, talking to, touching, etc., the individual. The sense organs will therefore be used not for recollecting impressions of psychic and external reality, but for expelling undesirable indigestible elements. Psychotic individuals, in their failure to develop the alpha function, will never differentiate unconsciousness from consciousness and will never sleep properly or fantasize.

Summarizing, the psychotic part of the personality is pictured as "[...] a tendency to aim at the destruction of all functions of unification, linking or joining of two objects" (Bleandonu, 1994, p. 136). In contrast, the nonpsychotic part of personality is concerned with linking, with matching two things for the emergence of a third. In this part resides the potential to build an apparatus to deal with thoughts and to 
make sense of feelings. As this thinking apparatus develops with the internalization of the mother's alpha capacity, the child should have the disposition to receive her products and tolerate her delays. Bion (1967a) noted that, for this to happen, there should be appropriate frustration tolerance, and a low amount of envy and death instinct, which imply the primacy of life instincts. In psychotics, all these factors occur the opposite way: the amounts of envy are enormous and the conflict instinct is never resolved. This inner hate prevents the baby from accepting what the mother gives, feeling envy of her capacities, and destroying the possibility of real contact with her. This envy and hate will increase with the difficulty to tolerate frustration. Bion noted this as fundamental in the incapacity to develop thoughts and a thinking apparatus. There are other cases in which an appropriate mother is lacking. Here, the baby is left alone in his attempts to process his unbearable feelings without containment. The only things the baby introjects are his own projections stripped of meaning: a nameless dread (Bion, 1962, 1967a). Mainly, matching a baby with an inborn predisposition to an adverse environment will foster psychotic functioning (O'Shaughnessy, 1992).

Bion's interest in understanding madness was remarkable, as was Freud's. Bion's findings from his work with psychotics enabled him to create a model for the acquisition of a thinking apparatus and development of thoughts, which may be absent or perverted in these individuals.

Many post-Kleinian authors give accounts of the phenomena described by Bion in their own clinical practice, reporting continual evidence for this model (Britton, 1992; Malcolm, 1992; Meltzer, 1986; O’Shaughnessy, 1988, 1992). For example, in Meltzer's clinical application of the concept of the "reversal of alpha function" to understand the material brought by a patient in a dream, he stressed the fact that Bion's conceptualizations of the attacks on linking and the dynamics of the beta elements that were expelled and became bizarre objects were enormously explanatory in comparison with the Kleinian theory before Bion. As another example, O'Shaughnessy (1988) reflected upon the importance of Bion's theory of thinking in psychoanalysis of children. Regarding some patients' attacks on the possibility of learning from analysis and finding meanings there, the study of Malcolm attempts to better understand the vicissitudes of this kind of patient within the setting, using these ideas. Britton exemplified failures in the container-contained model for the development of thinking with some clinical material.

In the case of Fonagy's model, clinical evidence is extensive. I have divided it into three groups: psychoanalysis of children, borderline patients, and violent individuals.

In working psychoanalytically with children, Fonagy and Target (1998) noted the need to change some aspects of the classical model, mainly, regarding the requirements children usually have to meet in order to become "psycho-analyzable." A special group, whose pathology compromised mainly their control of impulses, affecting regulation and self-monitoring, seemed to receive no benefit from the classical interpretative approach. These patients chiefly presented what could be called developmental pathology, showing a failure to mentalize. These "developmental arrests" are better understood when the reasons why the "arrest" occurred are examined. In most cases, these disorders were rooted in an inhibition of the mentalization capacity, as a defensive response toward an environment perceived as unsafe. This environment was almost always one in which the child was constantly exposed to trauma. Insofar as the reflective self develops by finding one's mind represented in the caregiver's, these children, instead of facing the sad reality of finding in their mother's mind a malevolent representation of themselves or harmful intentions toward them, chose instead to suspend the faculty of thinking about it, and along with it, the capacity to conceive of others and of themselves in a world of intentions, beliefs, and desires.

In these children, the problem is at the level of developing robust mental processes (Fonagy, Moran, Edgcumbe, Kennedy, \& Target, 1993). Here, the problem is not that there is an intolerable representation in the child's mind; what is intolerable is to have a mind that is able to produce representations. That is the reason for the inhibition of mentalization, as a defensive maneuver.

The incapacity to mentalize is also found In the case of adult borderline patients (Fonagy, 1991; Fonagy \& Target, 1995). Once again, an inadequate caregiver, unable to reflect upon her child's mental states but prone to react defensively or violently, will create in her mind a distorted representation of her child. The child, then, will internalize this distorted image of himself, feeling it as an alien part. Therefore, the borderline patient will desperately try to get rid of this alien part by placing it outside, in another person, whom he can hate, humiliate, or frighten. The need for the other's physical presence is, therefore, crucial for his psychological survival. It is the only way to make sure that this alien part will not return to him destructively. Dependence is understood within this framework (Fonagy \& Target, 1998), and suicide attempts are seen as the need to kill the alien part and liberate the self from it (Fonagy, Target, \& Gergely, 1999).

The instability shown by these patients also reveals their poor capacity to reflect and their lack of complex and flexible mental representations. Therefore, they only have one way to see reality and this makes them prone to anxiety and intolerance. The constantly used splitting mechanisms express their failure to achieve complete mental representations of themselves and of other selves. The feelings of emptiness that borderlines frequently complain of are related to their internalization of an empty representation of their own mind from the caregiver (Fonagy et al., 1999).

Most of the attacks borderline patients direct toward analysis and the analyst reveal an attack on the analyst's mental capacities and on the space designated to face mentalization, the setting. Their lack of empathy is related to the absence of a "theory of pain," through which one can imagine what the other is feeling. The diffusion of identity is related to their incapacity to have representations of mental 
states and self-images. This contributes to a lack of a sense of continuity in time that is crucial for a strong identity and object constancy, mourning processes, and individuation. Their difficulty in following associations and their confusion of language are also related to their incapacity to keep in mind the other's point of view and mental states (Fonagy, 1991).

Failures in mentalizing are frequently found in violent patients. Here, violent patients are not the ones belonging to the cycle of abuse, but the ones that show senseless aggression. Why would these individuals be violent if they had not been treated violently? Fonagy and Target (1995) explain that they have suffered a more subtle violence, one directed at the psychological self. There is no physical abuse but instead a mother in whose mind there was a no representation of her child as an intentional human being. Instead of that, there was a vacuum. This led to the internalization of a representation of the child which was felt as an alien part. The individual's harmful and violent acts reveal attempts to kill this alien part, or get rid of other painful thoughts. In a state of lacking a mind to represent ideas, the body is used as the vehicle to deal with thoughts and feelings: "The patient's unconscious fantasy may be that ideas reside in the body" (Fonagy \& Target, 1995, p. 495). In cases in which the mother is unable to reflect upon her child, there should be a father who, perceiving his child and the relation between mother and child, lets the baby know that he, the baby, is in interaction with another self and takes part in an intersubjective relationship.

In both models, there is emphasis on clinical findings. The idea of inhibiting or attacking the entities that make it possible to think and have mental representations is quite similar, and as is the way this is observed in clinical settings in terms of attacks directed at the analyst and at analysis. The nameless dread and the internalization of a vacuum seem to be similar concepts. Both authors are concerned with understanding severe psychopathologies.

In terms of experimental, or empirical, evidence, I have only found data about Fonagy's model. This is probably due to this author's special interest in reaching a scientific stance inside and outside the psychoanalytic community. For that reason, even the language employed in this model is more akin to the one used in developmental or cognitive psychology. However, the difference may be that, in this model, a metacognitive capacity such as mentalization is achieved in interaction with other figures, and the role of emotions and affects is always noted. There are numerous investigations from the psychological field that justify the model of mentalization; however, they will not be discussed here. These investigations are mainly related to evidence that supports the different ways of experiencing psychic reality mentioned above, and the importance of the involvement of all the family members in the integration of a reflective function (Fonagy \& Target, 1996b). The above-mentioned relationship between mentalization and attachment security is very interesting in terms of evidence. One of the most important conclusions of the London Parent-Child Project was that parents who are capable of conceiving relationships and interactions in terms of mental processes will be more sensitive to recognize their children's needs; this will make their children feel safe and become securely attached. In a safe relationship, the possibility to think about one's own and others' mental states is guaranteed. Therefore, these children will be able to mentalize and, as adults, they will become sensitive towards their own children's needs. The benign cycle is reproduced and a transgenerational transmission of the reflective function addressed (Fonagy et al., 1991).

In this discussion of empirical evidence, it is worth remembering that Bion, enormously interested in granting a scientific status to psychoanalysis, as Fonagy also seems to be, focused more on meta-psychology than on empirical research. However, Bion, in the first paragraph of his "A theory of thinking," said: "It is devised with the intention that practicing psychoanalysis should restate the hypothesis of which it is composed in terms of empirically verifiable data" (Bion, 1967a, p. 110).

The numerous illustrations of Fonagy's model about the defensive nature of the inhibition of mentalization in borderline patients, for example, could be seen as empirical support of Bion's ideas on the attacks some people carry out against the awareness of reality and the tendency to avoid the frustration that it entails. Likewise, we could say that Bion's ideas about attacks on linking are theoretical support for Fonagy's ideas about how the patient, when in analysis, keeps attacking the analyst's mind and the setting, as a space where mental capacities should emerge. In one way or another, both models could be used to support each other. There is a kind of mutual external validity.

Looking at the etiology of the incapacity to think and the arrested capacity of mentalization, it could be said that there is a defensive purpose behind both of them. The avoidance of frustration by the baby in a state of psychic pain and need leads him to attack and obscure his own apparatus for gaining awareness of psychic and external reality. Inhibiting a mental capacity so as to be unaware of the parent's mental representations about the baby is, as in the other case, a defensive maneuver. Both models seem to agree about the defensive nature of the impossibility of achieving mentalization and thinking processes, and the need to avoid psychic pain. However, the difference would be found in the weight given by each model to innate and environmental triggers. As observed, in Bion's model, there is a strong innate component for not developing an adequate thinking apparatus and thoughts: frustration intolerance, a high amount of death instinct manifested in envy. Also, there must be a mother who is incapable of performing reverie. In contrast, in Fonagy's model, emphasis is almost entirely on the caregiver, as this author constantly reminds readers of the interpersonal nature of his model.

I have mainly described the clinical evidence I have found in each model, but clinical formulations of psychopathology convey technical issues. This is our next subject. 


\section{Consequences of the Theory of Technique}

The container-contained model is a useful framework to understand psychoanalytic technique (Spillius, 1992). In the setting, patient and analyst somehow repeat the very early relationship between baby and mother. The patient projects his mental contents onto the analyst all the time, and she contains and processes them with her reverie. Moreover, the psychoanalytic setting, as a space in itself, is seen as a container of what happens within it. The experience of containment, as an inherent part of the setting, is considered therapeutic in itself. Fonagy's model, in a similar way but in different terms, considers the analytic relationship, mainly when working with children, as one that, of its own accord, provides an aid to the child: a developmental aid. For example, when playing with a child in the setting, the analyst, as a benign person, offers his mind to be explored freely by the child. In this process, the child is repeating a part of his development, but in a safe setting, benefiting from the experience of the relationship itself. By enabling him to experience the analyst's mental activity, the child is thus helped to understand his own psychic reality (Fonagy, 1989; Fonagy \& Target, 1998).

Interpretation has always been the main technical tool in psychoanalysis. However, with patients whose capacities to mentalize are inhibited, the classical interpretative approach is not useful. Instead, the reflective function can be promoted if, within the setting, the patient is step-bystep invited to think, not about his unconscious motivations and past experiences, but about what he believes is going on in the analyst's mind. This technical tool is justified by the fact that human beings become intentional beings by finding a representation of their own selves as intentional individuals in someone else's mind. Therefore, transference interpretations centered on the analyst are more useful to help people with these problems. Steiner (1993) refers to patients who do not want to understand but want to be understood. In such cases, analyst-centered interpretations and clarifications are useful. These ideas from the Kleinian school seem to match Fonagy's. Only when the patient's exploration of the analyst's mind has led to the reactivation of his own mental processes, will he be ready for more classical psychoanalytic work. Likewise, only when the patient finds a clear boundary between external and internal reality he can withdraw his own projections, regain his capacity to mourn (Steiner), and, in Fonagy's terms, be ready for real intersubjective contact with others.

According to Grinberg, et al., (1993), for Bion, an interpretation "[...] formulates in simple terms the beliefs that the patient has about the analyst and the analysis" (p. 118). This idea echoes the emphasis or the use of interpretations centered on what the patient thinks the analyst is thinking, proposed by Fonagy for people with mentalization difficulties. However, when the analyst is faced with a problem related to the patient's inability to integrate a mental representation that has been distorted or barred during his development, she interprets the conflict brought by this painful or shameful mental representation. It seems that, from a Kleinian tradition, Bion's use of interpretation is more directed at tackling the contents of unconscious fantasy expressed in the here-and-now of the transference processes whereas, in Fonagy's model, the analyst must wait until the inhibited mental process have been activated to provide deep interpretations and deal with unconscious motivations. The importance of the analyst as a container of what is incomprehensible for the patient and his involvement in trying to find meaning and representation for these feelings is something that both models seem to share.

O'Shaughnessy (1988) notes that Bion's theory of thinking, mainly the vicissitudes of the $\mathrm{K}$-link, is a very important tool for the technique of child psychoanalysis. $K$ is the notation for "knowing;" this is a basic human kind of object relation that allows us to know something, it establishes links between ourselves and other selves, and things in the world (Thorner, 1981), allowing emotional understanding (O'Shaughnessy). $\mathrm{K}$ is formed in the first exchanges between mother and baby, where projective identification is the way the baby communicates with its mother, and the way the mother knows and understands what is going on with her baby. K, therefore, emerges from an emotional experience. An individual's limit to knowing or being known depends on how successful or unsuccessful these experiences were. Due to innate factors such as the baby's envy or the mother's inadequate nurturing, the emotions that would otherwise be known and understood by her remain misunderstood and stripped of their meaning, and the result is a person who misunderstands himself and others. In other cases, when the psychotic part of the personality takes control, the individual is condemned to live in an unreal universe, surrounded by bizarre objects. Bion calls the first case Minus $K(-K)$ and the latter No $K$. In the emotional quality of the process of knowing and thinking resides the particularity of Bion's ideas and the clue to understanding what is happening in the therapeutic process.

Likewise, in Fonagy's model, emotions and affects are cornerstones for developing mentalization (Fonagy, 1989). The kind of emotional experience undergone in the first relationships will either promote or inhibit the reflective function. In pathology, the pain, mistreatment, and sorrow experienced during infancy will demarcate the limits of what the patient is subsequently able to think or represent mentally. Fortunately, via the new emotional experience undergone with the analyst, this inhibition can be changed to reactivation of the mental capacities. Moreover, the emotions themselves will find, in the analytic space, proper recognition and understanding by the patient (Fonagy \& Target, 1998).

Bion expresses a very interesting idea about the practice of psychoanalysis. He says that the analyst should be able to intuit a patient's emotion before it becomes painfully obvious to the patient. The aim of this intuitive capacity is to avoid unnecessary pain for the patient. For Bion, pain is already part of the process of knowledge that is present in 
any analysis. The constant dialectic movements between schizoid-paranoid and depressive positions enable the patient to tolerate psychic pain, which is necessary for development and change. It could be said that this intuition is somehow be driven by the analyst's capacity to unconsciously scan the mental states perceived in the patient and this, in Fonagy's terms, resembles the reflective function.

Let us return to pain. According to Thorner (1981), knowing and thinking imply displeasure and pain, and require a capacity for tolerating frustration. If there is no capacity to tolerate absence, the capacity to think will never develop (Bion, 1967a). Joseph (1981) adds that tolerating pain in the therapeutic process is a prerequisite for feeling better and for having a true experience of what pleasure is. Psychoanalytic treatment aims at gaining insights about oneself and this implies the pain of knowing. Pain is part of the personality and is present in any acquisition of knowledge (Grinberg, 1988). This idea of pain as part of growing is also present in Fonagy's model in relation to the activation of mental processes within the setting. The inhibition of mental processes in the course of development due to mistreatment or trauma comes from a defense against pain: the pain of realizing that there were distorted images of the child and harmful intentions toward him in his mother's mind. As mentioned, the psychoanalytic process within this model implies a space for thinking about what thinking is, and, for someone who has become afraid of mental contents, this can be a very painful task. However, the analyst represents a benign individual to whom the patient can relate. Also, the analytic relationship constitutes a safe space in which to help the patient to overcome his fears about what a mind is, and in time, he will be able to reactivate his mentalizing stance. Only after this can a more classic technical approach be applied.

For Bion (1967b), the analyst should allow the analytic process to unfold freely without interference from his desires or memories. A desire for cure or results must be left aside, as well as any deliberate attempt to remember past sessions. Instead of that, every session should be seen as complete, not only as a part of the psychoanalytic process but also as a process in itself. This means that the patient develops not only over a period of time but within every session. Therefore, the analyst "[...] should aim at achieving a state of mind so that, at every session, he feels he has not seen the patient before" (Bion, 1967b, p. 18).

Contrariwise, for Fonagy, in the therapeutic process, the analyst deliberately intends to place the patient in situations where he is required to think about, for example, what is in the analyst's mind. This "more directive" and focused approach responds to a need to reactivate the mental processes arrested in the patient, as a prerequisite for more profound psychoanalytic work with him. Psychoanalytic work implies a capacity to reflect upon one's own mental states; if this capacity is absent, something must be done to achieve it. Obviously, this is achieved by using psychoanalytic methods and psychoanalytic understanding; the result is positive because the range of patients who are able to be treated psychoanalytically increases. Fonagy's (Fonagy \& Bateman, 2006) therapeutic model has been recently turned into a manual for purposes of training and outcome research.

The introduction of a different technical approach for people with inhibited mental capacities and the model's focus on container-contained to understand the psychoanalytic relationship seem to be the most important technical issues in these theories.

\section{Thinking and Mentalizing: A Developmental Sequence?}

Can thinking really be considered the seed of mentalization? Obviously, from a purely epistemological perspective, there are some impediments to this notion. Bion's model still has the remains of an internalistic way of understanding mental states. However, the process in which he believes mental states and capacities to be developed takes place in an intersubjective scenario. As noted above, his model can be placed in an intermediate epistemological position between a pure internalistic and a contemporary intersubjective understanding of the mind. That means that Bion's model is relatively close to Fonagy's, which is completely based on the Davidsonian idea that mental states and processes are constructed in a public and social understanding of the mind. But how can an integrative epistemological position for both models be found? I believe that such a position should meet two requirements. On the one hand, it must prevent subjectivity from being absorbed by intersubjectivity; that is, it must reserve a space for the particularities of the subjective experience. On the other hand, it needs to recognize that subjectivity is constructed relationally and not privately. In brief: even though the nature of mental sates is intersubjective, the basis of subjectivity relies on the body and its instinctual dynamics, which are also experienced from the beginning in a relational scenario. Following Bejamin (1995), a creative tension between the intrapsychic and the intersubjective domains of mental life should be maintained in order to gain an appropriate psychoanalytic understanding of mental processes.

The current predominance of relational or so-called "two person" models of the mind in psychoanalysis (Mitchell, 1988) constitutes an interesting starting point to reorganize classical meta-psychoanalytic concepts such as drive, desire, and so on, within an intersubjective framework. This could also give psychoanalysis the chance to dialogue with neurosciences, developmental psychology, and cognitive science. If these ideas about a mind constituted intersubjectively are taken into account, I think is possible to say that thinking is the seed of mentalizing and that both of them are part of the same developmental line. 


\section{References}

Benjamin, J. (1995). Like subjects, love objects. Essays on recognition and sexual difference. New Haven, CT: Yale University Press.

Bion, W.R. (1962). Learning from experience. London: Karnac.

Bion, W.R. (1967a). Second thoughts. London: Maresfield Library.

Bion, W.R. (1967b). Notes on memory and desire. In E. Spillius (Ed.), Melanie Klein today. Developments in theory and practice. Vol. 2. Mainly practice (pp. 17-21). London: Routledge.

Bion, W. (1988). Elementos del psicoanálisis. Buenos Aires: Paidós.

Bleandonu, G. (1994). Wilfred Bion. His life and works. 18971979. London: Free Association Books.

Britton, R. (1992). Keeping things in mind. In R. Anderson \& H. Segal (Eds.), Clinical lectures on Klein and Bion (pp. 102113). London: Routledge.

Cavell, M. (1993). The psychoanalytic mind. From Freud to philosophy. Cambridge, MA: Harvard University Press.

Fonagy, P. (1989). On tolerating mental states: Theory of mind in borderline patients. Bulletin of the Anna Freud Centre, 12, 91-115.

Fonagy, P. (1991). Thinking about thinking: Some clinical and theoretical considerations in the treatment of a borderline patient. International Journal of Psychoanalysis, 72, 639-656.

Fonagy, P., \& Bateman, A. (2006). Mentalization-based treatment for borderline personality disorder : A practical guide. New York: Oxford University Press.

Fonagy, P., \& Moran, G. (1991). Understanding psychic change in child psychoanalysis. International Journal of Psychoanalysis, 72, 15-22.

Fonagy, P., Moran, G., Edgcumbe, R., Kennedy, H., \& Target, M. (1993). The roles of mental representation and mental processes in therapeutic action. Psychoanalytic study of the child, 49, 9-48.

Fonagy, P., Steele, M., Steele, H., Moran, G., \& Higgit, A. (1991). The capacity for understanding mental states: The reflective self in parent and child and its significance for security of attachment. Infant mental health journal, 12, 201-218.

Fonagy, P., \& Target, M. (1995). Understanding the violent patient: The use of the body and the role of the father. International Journal of Psychoanalysis, 76, 487-501.

Fonagy, P., \& Target, M. (1996a). Playing with reality: I. Theory of mind and the normal development of psychic reality. International Journal of Psychoanalysis, 77, 217-233.

Fonagy, P., \& Target, M. (1996b). Playing with reality: II. The development of psychic reality from a theoretical perspective. International Journal of Psychoanalysis, 77, 459-479.

Fonagy, P., \& Target, M. (1997). Attachment and reflective function: Their role in self-organization. Development and psychopathology, 9, 679-700.

Fonagy, P., \& Target, M. (1998). Mentalization and the changing aims of child psychoanalysis. Psychoanalytic dialogues, 8, 87114.

Fonagy, P., Target, M., \& Gergely, G. (1999, March). A new transgenerational theory of self-development. Paper presented at the IPTAR conference on the Evolution and Dissolution of the Self, New York.
Grinberg, L. (1988). Prólogo. Presentación a la versión castellana. (Prologue Presentation of the Spanish version). In W.R. Bion, Elements of Psychoanalysis. New York: Basic Books (Original work published 1962). (Spanish translation: Elementos del psicoanálisis ( $2^{\text {nd }}$ ed.; pp. 7-10). Buenos Aires: Paidos, 1988).

Grinberg, L., Sor, D., \& Tabak de Bianchedi, E. (1993). New introduction to the work of Bion (revised edition). London: Aronson.

Hinshelwood, R.D. (1991). A dictionary of Kleinian thought. London: Free Association Books.

Joseph, B. (1981). Toward the experiencing of psychic pain. In J.S. Grotstein (Ed.), Do I dare disturb the universe? A memorial to W.R. Bion (pp. 94-102). London: Karnac.

Lansky, M. (1981). Philosophical issues in Bion's thought. In J.S. Grotstein (Ed.), Do I dare disturb the universe? A memorial to W.R. Bion (pp. 428-440). London: Karnac.

Malcolm, R. (1992). As if: The phenomenon of not learning. In R. Anderson, \& H. Segal (Eds.), Clinical lectures on Klein and Bion (pp. 114-125). London: Routledge.

Meltzer, D. (1986). Studies in extended meta-psychology. Clinical applications of Bion's ideas. Somerset. UK: Trust Clunie Press.

Mitchell, S. (1988). Relational concepts in psychoanalysis. An integration. Massachusetts: Harvard University Press. [Spanish translation: Conceptos relacionales en psicoanálisis: Una integración. México DF: Siglo XXI, 1993.]

O'Shaughnessy, E. (1988). W.R. Bion's theory of thinking and the new techniques in child analysis. In E. Spillius (Ed.), Melanie Klein today. Developments in theory and practice. Vol. 2. Mainly practice (pp. 177-189). London: Routledge.

O'Shaughnessy, E. (1992). Psychosis: Not thinking in a bizarre world. In R. Anderson \& H. Segal (Eds.), Clinical lectures on Klein and Bion (pp. 89-101). London: Routledge.

Snelling, D. (2001). Philosophy, psychoanalysis and the origins of meaning. Pre-reflective intentionality in the psychoanalytic view of the mind. Aldershot: Ashgat

Spillius, E. (1992). Clinical experiences of projective identification. In R. Anderson \& H. Segal (Eds.), Clinical lectures on Klein and Bion (pp. 59-73). London: Routledge.

Steiner, J. (1992). The equilibrium between the paranoid-schizoid and depressive positions. In R. Anderson \& H. Segal (Eds.), Clinical lectures on Klein and Bion (pp. 46-58). London: Routledge.

Steiner, J. (1993). Problems of psychoanalytic technique: Patient centered and analyst centered interpretations. In J. Steiner, Psychic retreats. Pathological organizations in psychotic, neurotic and borderline patients (pp. 131-146). London: Routledge.

Thorner, H. (1981). Notes on the desire for knowledge. In J.S.Grotstein (Ed.), Do I dare disturb the universe? A memorial to W.R. Bion (pp. 590-599). London: Karnac.

Wisdom, J.O. (1981). Meta-psychology after forty years. In J.S.Grotstein (Ed.), Do I dare disturb the universe? A memorial to W.R. Bion (pp. 602-624). London: Karnac.

Received March, 29, 2006

Revision received January, 12, 2007

Accepted February, 6, 2007 